Artículos

\title{
Agua y reforma agraria: una hacienda del altiplano mexicano, 1918-1946
}

Water and Agrarian Reform: a hacienda of the Mexican highlands, 1918-1946

Verenice Cipatli Ramirez Calva

DOI: https://doi.org/10.24215/15155994e141

Universidad Autónoma del Estado de Hidalg, México

Redalyc: http://www.redalyc.org/articulo.oa?id=84563515003

verenicecipatli@yahoo.com.mx

Recepción: 17 Octubre 2019

Aprobación: 20 Enero 2020

\section{Resumen:}

En el presente artículo se analizan los efectos de la Ley Agraria de 1915 en los sistemas de riego construidos por pueblos y haciendas. No obstante que la citada ley no ordenó la dotación de agua, los ejidatarios hicieron uso de ella, cuestión que generó varios conflictos entre usuarios. La discusión se aborda a través del estudio de uno de los latifundios más extensos de la región, la hacienda San Servando Tlahuelilpan, en suroeste del estado de Hidalgo. A través del estudio de documentos históricos y resoluciones presidenciales con las que se concedieron ejidos, se concluye que la reforma agraria abrió la puerta a demandas de afectados no solo con la expropiación de tierras sino también con la apropiación del agua y obras hidráulicas por parte de los ejidatarios.

Palabras Clave: Reforma agraria, Haciendas, Ejidos, Agua, México.

\begin{abstract}
:
This article analyzes the effects of the Agrarian Law of 1915, which created the ejido in Mexico, in irrigation systems built by towns and farms. Although that law did not order the provision of water, the ejidatarios made use of it; this situation generated conflicts between users. The discussion is addressed through the study of the productive unit San Servando Tlahuelilpan, in the southwest of the state of Hidalgo, one of the largest large estates in the region. The period studied is centered between 1918 and 1946. The investigation is based on historical documents and presidential resolutions with which ejidos were granted. It is concluded that the agrarian reform opened the door to demands from those affected not only with the expropriation of land but also with the appropriation of water and hydraulic works by ejidatarios.
\end{abstract}

KEYWORDS: Land Reform, Haciendas, Social property, Water, Mexico.

\section{INTRODUCCIÓN}

En años recientes la historiografía ha vuelto la mirada al impacto que la ley agraria expedida el 6 de enero de 1915 ocasionó en las formas de gestión del agua y su gobernanza de los sistemas de riego en México. Esa ley ordenó la dotación o restitución de tierras a los pueblos que carecieran de ellas o a los que por falta de títulos les fuera imposible demostrar su propiedad. Si bien en ninguno de sus artículos se indicó explícitamente que junto con la tierra se concedía el agua, en los hechos al estar los canales de riego de haciendas o pueblos ubicados dentro de los límites de los nuevos ejidos, los beneficiarios del reparto agrario simplemente hicieron uso de ellos. Esta situación generó un clima de tensión y conflicto entre antiguos y nuevos usuarios de los sistemas de riego, las entidades federativas y el gobierno federal. Los sistemas de irrigación, que terminaron por ser absorbidos por los ejidos, fueron construidos por hacendados, pueblos y rancheros durante un largo proceso histórico.

En este artículo retomamos la discusión mediante el estudio de la hacienda San Servando Tlahuelilpan, localizada en el suroeste del estado de Hidalgo, México (Ver Figura 1). Nos interesa conocer cómo esa unidad productiva perdió el control sobre los sistemas de riego que aprovechaba a consecuencia de la implementación de la reforma agraria. Si bien San Servando accedió al agua de dos caudales, en esta ocasión ponemos especial atención a aquellos sistemas de irrigación derivados del río Salado. En el presente consideramos que la falta de claridad en la ley agraria y los procedimientos legales para la obtención de agua hicieron que autoridades 
agrarias y nuevos ejidatarios asumieran que al dar y recibir dotaciones de tierra, el agua se obtenía por accesión. Las pugnas legales por el aprovechamiento del agua generadas por la ley de 1915 son muestra de esa falta claridad, que el gobierno federal intentó resolver con la posterior expedición de otras leyes. El periodo a estudiar lo constreñimos a los años que van de 1918 a 1946 porque durante ese lapso le fue expropiada a la hacienda gran parte de su superficie para la dotación y ampliación de ejidos. Como consecuencia del reparto agrario la hacienda sufrió sucesivas "invasiones" a sus canales de riego hasta llegar a la pérdida total del control sobre el suministro de agua.

En Apuntes sobre irrigación José Herrera y Lasso (1994) planteó que en el siglo XIX se inició en México una tendencia centralizadora en materia de agua y tierra. Ese proceso se inauguró con la constitución de 1857 y se acentuó con las leyes del 5 de junio de 1888, 6 de junio de 1894, 17 de diciembre de 1896, 18 de diciembre de 1902 y 13 de diciembre de 1910 hasta perfeccionarse en el artículo 27 de la constitución de 1917. Décadas después varios historiadores han desarrollado puntualmente el mismo argumento (Aboites, 1997; Aboites y Estrada, 2004; Escobar, 2009; Birrichaga, 2009, entre otros).

Figura 1. El valle de Tula

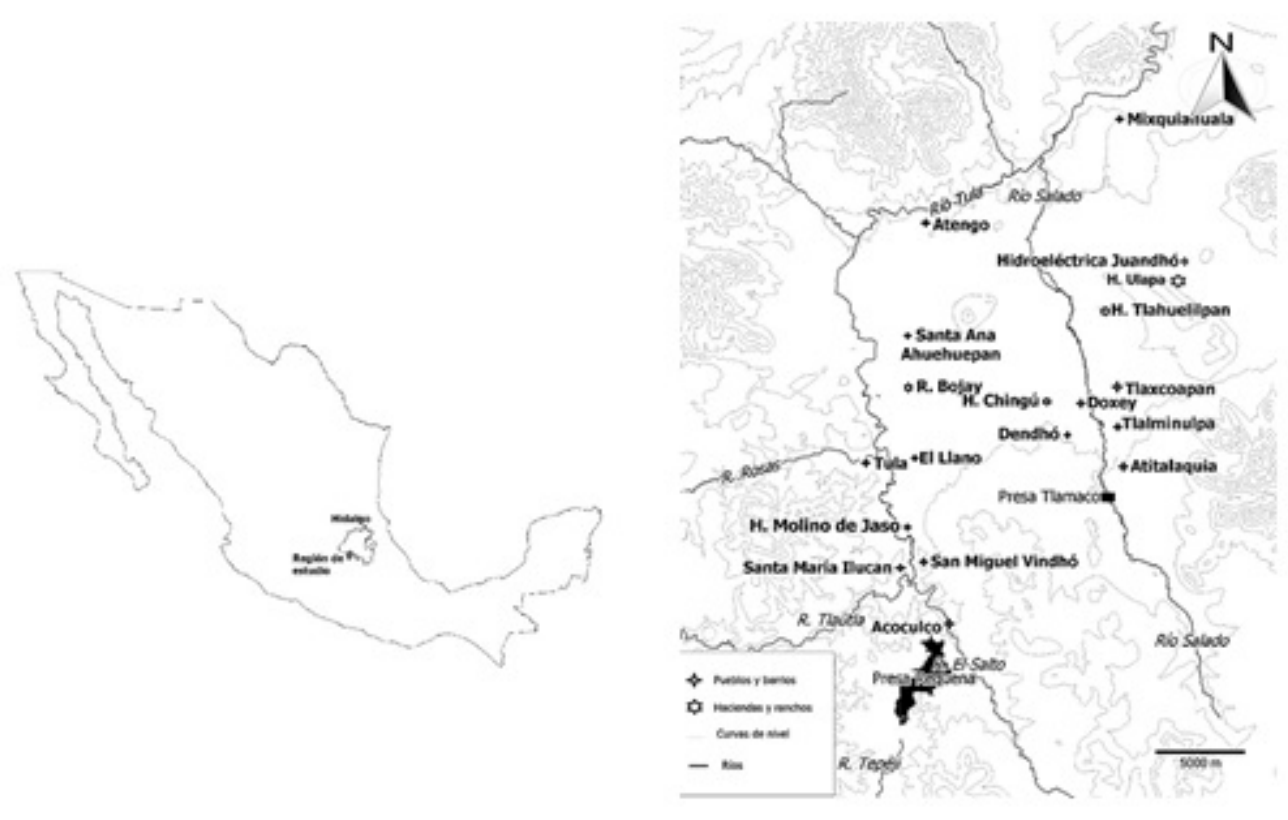

Elaboración propia

El paso decisivo hacia la centralización en el manejo del agua ocurrió el 5 de junio de 1888 con la publicación de la Ley de Vías Generales de Comunicación. En ella se establecieron como vías generales de comunicación no solo los caminos y ferrocarriles, sino que también incluyó los mares territoriales, esteros, lagunas, canales construidos por la federación, lagos, ríos navegables o flotables o que marcaran los límites del territorio nacional o entre entidades federativas. El ejecutivo federal se erigió como la instancia a la cual correspondía la vigilancia de esas vías y su reglamentación, mientras que la Secretaría de Fomento fue la encargada de extender las confirmaciones de derechos de agua. A su publicación siguió el esfuerzo del estado mexicano para conocer las corrientes de agua y su posterior declaratoria como parte de la jurisdicción federal (Herrera, 1994, p. 132; Escobar, 2009, p. 64). Si bien esa ley fue un punto de partida para que el estado atrajera el dominio eminente sobre el agua, no estableció la propiedad sobre ella, únicamente contempló la jurisdicción, de manera que no podía intervenir en asuntos como la distribución o concesión del líquido. Mientras tanto, al no incluir la figura de la concesión abrió la puerta para que antiguos títulos coloniales continuaran vigentes (Camacho y Chávez, 2017, p. 399). Varios estudiosos han planteado que esa ley impulsó un largo proceso en el que ayuntamientos, comunidades de regantes y propietarios privados perdieron el 
control sobre el agua. Ejemplo de ese complejo proceso es el litigio entre la Compañía del Tlahualilo y el gobierno mexicano (Romero, 2002, 2006, 2007). Conflictos similares se sucedieron en el río Atoyac, Puebla, y el Duero en Michoacán (Sánchez, 1993). La injerencia del estado en materia hídrica fue ampliamente cuestionada por juristas, empresarios, entidades federativas y gobiernos locales (Aboites, 1997; Topete y Méndez, 2019; Rosas, 2013). Edgar Mendoza (2013) ha documentado cómo en algunos municipios en los que el agua constituía un ingreso económico importante lograron, mediante diversos mecanismos, resistir el proceso de federalización. A pesar de la oposición, varias entidades federativas emitieron constituciones en las que se adhirieron a las disposiciones del gobierno federal, tales fueron los casos de Michoacán, Jalisco y Oaxaca (Sánchez, 1993). Sin embargo, el estado de Hidalgo no legisló en materia de agua sino hasta su constitución de 1920, en cambio, se alineó a lo establecido en la constitución federal de $1917{ }^{1}$

En 1910 fue dictada en México la primera ley de aguas propiamente dicha, cuya vigencia se extendió hasta 1929. Estaba dirigida a empresarios y pequeños propietarios como solicitantes de agua. Su principal aportación fue haber dejado bajo jurisdicción federal todos los recursos hídricos del país, considerándolos de dominio público y uso común, por lo que eran inalienables. A partir de entonces fue competencia del ejecutivo federal, mediante la Secretaría de Fomento, otorgar concesiones de agua, confirmar derechos y celebrar contratos de colonización con los respectivos concesionarios. Además, esta ley facultó al ejecutivo federal para reglamentar el uso de agua, por lo que derechos antiguos igualmente podían ser modificados. En adelante, la instancia encargada de reglamentar y tramitar los expedientes de concesión para uso y aprovechamiento de agua de jurisdicción federal fue la Secretaría de Fomento (Escobar, 2009; Sánchez y Escobar, 2008; Camacho y Chávez, 2017).

Por otro lado, la ley agraria expedida en 1915 por Venustiano Carranza, primer jefe del Ejército Constitucionalista, encargado del Poder Ejecutivo de los Estados Unidos Mexicanos, fue elaborada por Luis Cabrera Lobato. Está integrada por nueve considerandos, 12 artículos y un transitorio. En ella se declararon nulas las enajenaciones de tierras, aguas y montes hechas a los pueblos en contravención a la ley del 25 de junio de 1856. Igualmente anuló las concesiones, composiciones o venta de tierras efectuadas por la Secretaría de Fomento a partir del 1 de diciembre de 1876. En su artículo tercero ordenó que a los pueblos carentes de ejidos o títulos que los ampararan en su propiedad se les dotara de terreno suficiente conforme a las necesidades de su población; dichos terrenos debían ser expropiados a los latifundios colindantes por cuenta del gobierno nacional. Mediante esta ley se creó la Comisión Nacional Agraria, a cargo de la Secretaría de Fomento, así como una comisión local agraria por cada entidad federativa, y el número de comités particulares ejecutivos acorde con las necesidades de cada estado (Ley del 6 de enero de 1915).

Posteriormente, tanto la ley de aguas de 1910 como la agraria fueron integradas al artículo 27 de la constitución de 1917. En él se consolidó la política del estado en materia de propiedad y dominio de recursos al establecer que las tierras y aguas comprendidas en el territorio nacional pertenecían a la nación, y ella era la única que podía trasmitir el dominio a particulares (Constitución Política de los Estados Unidos Mexicanos, 1917; Camacho y Chávez, 2017, pp. 393, 394).

Después de 1915 la forma de acceder al agua en México fue a través de una concesión gubernamental amparada en la ley de 1910. Mientras tanto, los ejidatarios de facto accedieron a ella al recibir restitución, dotación o ampliación de ejidos a pesar de que las resoluciones presidenciales no lo indicaran (Camacho y Chávez, 2017). El problema radicaba en que la ley agraria únicamente contempló explícitamente la dotación o restitución de tierra, pero no la de agua. No es difícil entonces entender que el reparto agrario propició tensión entre la antigua comunidad de regantes y los nuevos usuarios, que se apropiaron y a veces modificaron los sistemas de riego, y contriuyeron a trastocar los acuerdos que habían posibilitado la gestión y acceso al agua de manera relativamente pacífica durante siglos (Serrano, 2002; Valladares, 2003; Escobar, 2013). El 6 de noviembre de 1923 ese asunto se intentó aclarar mediante un decreto según el cual "siempre que exista un antagonismo entre las concesiones y confirmaciones de aguas a particulares y las dotaciones o restituciones de las mismas solicitadas por los núcleos de población antes enumerados, debe darse la preferencia de estos sobre 
aquellos". Añadió asimismo que acorde con el artículo 27 de la constitución los pueblos y comunidades tenían derecho no solo a tierras sino también a aguas; ésta debía entenderse como una accesión de la tierra. Con este decreto se adicionó un artículo al reglamento agrario de 1922 en el que se asentó que pueblos, rancherías, congregaciones, condueñazgos y comunidades tenían derecho a solicitar tierras en dotación y restitución. Ordenó también que las referidas corporaciones tenían derecho preferente al uso y aprovechamiento de aguas de jurisdicción federal para cubrir necesidades agrícolas. ${ }^{2}$ No obstante, el reglamento agrario no aclaró los procedimientos para dotar agua.

Luis Aboites ha señalado que en los años posteriores a la reforma agraria no se expidieron reglamentos que aclararan los procedimientos a seguir para obtener dotación de aguas a los ejidos. Ello es evidente, a decir del autor, en los considerandos de la ley de irrigación expedida por Calles en 1926. Aboites apunta que ahí "parecía que el agua se había olvidado", aspecto en el que concuerda Antonio Escobar (2013). De acuerdo con la interpretación de aquel, el gobierno federal intentó paliar la falta de claridad legal existente con la ley de 1926, que contempló la entrega de agua a ejidatarios por vía de la accesión, ya sea durante o después del proceso de dotación de tierras, pero siempre con la condición de que las resoluciones presidenciales hubiesen concedido explícitamente "tierras de riego" (Aboites, 1997, p. 133). Entre la promulgación de la ley de aguas de 1910 y su reforma en 1929 los gobiernos posrevolucionarios se dedicaron a legislar en asuntos agrarios (Sánchez y Escobar, 2008). El tema hídrico fue abordado hasta 1927 con la ley de "Dotaciones y restituciones de tierras y aguas", en la que se planteó la dotación de agua, procedente solo cuando un ejido hubiera sido dotado de tierras de riego y en los casos en que no hubiera recibido el agua. No fue sino hasta 1929 cuando se publicó una nueva ley de aguas que atendió las trasformaciones generadas por la legislación agraria, y que habían rebasado a la ley de 1910. La ley de 1929 abrió la posibilidad de modificar las concesiones de agua ya otorgadas para dar cumplimiento a las leyes agrarias. Uno de sus aspectos más polémicos es que dio al estado la facultad no solo para dotar el agua, sino también reglamentar su uso y la organización de los usuarios. Por otro lado, en 1934 se emitió el código agrario en el que explícitamente se ordenó que si una dotación ejidal afectaba más del $75 \%$ de las tierras favorecidas con una obra hidráulica, esta debía ser comprendida en la dotación ejidal (Aboites, 1997, pp. 137). Con la ley de 1929 y el código de 1934 la falta de claridad legal en torno al ejido y al agua quedó zanjada legalmente, pero, entretanto, ejidatarios, propietarios privados, ya fueran dueños de ranchos, haciendas, pequeñas parcelas de cultivo, entraron en conflicto por el acceso al agua.

Para lograr la compresión de ese proceso en el caso que aquí se estudia, en las siguientes líneas abordamos algunos aspectos de la hacienda como su ubicación, propietarios y extensión territorial desde finales del siglo XIX hasta principios de la siguiente centuria. Con esos elementos claros se explicará después cómo fue desmembrada territorialmente la hacienda y en qué momentos de eso proceso fue perdiendo el control sobre sistemas de riego, así como la respuesta de sus propietarias y representantes legales ante lo que consideraban como "invasiones". Al final del texto se mostrará que los posteriores conflictos por el agua, originados en el aumento en el número de usuarios y volumen utilizado, llevaron a la formación de juntas de agua, pero no a la solución de las disputas.

\section{La hacienda San Servando Tlahuelilpan}

A principios del siglo XX el estado de Hidalgo estaba conformado por 15 distritos y 71 municipios, y, de acuerdo con el censo de 1910, su población ascendía a 646.551 habitantes. El pueblo de Tlahuelilpan y la hacienda del mismo nombre formaban parte del municipio de Tlaxcoapan, cuya población sumaba los 3.309 habitantes. En Tlahuelilpan había 866 habitantes, mientras que en la hacienda residían 163 personas. Las principales actividades económicas del grueso de la población eran el peonaje en el campo y el servicio doméstico ( Tercer Censo de Población de los Estados Unidos Mexicanos, 1910).

La hacienda San Servando permaneció en manos de los descendientes de los condes de la Cortina por cerca de 78 años. Durante ese tiempo los sucesivos poseedores acrecentaron sustancialmente su superficie 
e implementaron mejoras, encaminadas a obtener altos rendimientos agrícolas, como la construcción y ampliación de sistemas de irrigación. El último miembro de ese linaje en poseer el patrimonio familiar fue el intelectual y político José Justo Gómez de la Cortina, cuyos malos manejos de su herencia lo obligaron a vender las haciendas de San Nicolás Ulapa, San Servando y los ranchos de Teocalco, Santa Bárbara y San Antonio Atotonilco al rico comerciante originario de Pátzcuaro, Francisco María Iturbe y Anciola. Posteriormente Iturbe y Anciola las heredó a sus hijos, Francisco y Manuel Adrián. A principios del siglo XX este último era dueño de Ulapa y San Servando, que juntas conformaban uno de los latifundios más extensos de la región (Castillo, 2008; Martínez, 2004, pp. 224-227). ${ }^{3}$

Durante el gobierno de Porfirio Díaz, Manuel Adrián Iturbe y del Villar fue nombrado enviado extraordinario y ministro plenipotenciario en varios momentos, de 1894 a 1899, para representar a México en Alemania, y de 1899 a 1904, en España. Cuando fungió como embajador en Francia contrajo matrimonio con la malagueña Trinidad von Scholtz Hermensdorff. Con ella procreó a María de la Trinidad Cipriana Raimunda Piedad Iturbe von Scholtz Hermensdorff, tercera marquesa de Belvis de las Navas, quien a su vez contrajo nupcias con el príncipe alemán Max Egon de Hohenlohe Langerburg (Tovar y Marín, 2009, pp. 109, 112). A la muerte de don Manuel, acaecida en 1904, su esposa e hija heredaron sus cuantiosos bienes. A él pertenecían las haciendas de Taretan en Michoacán y San Nicolás en Tlaxcala; en Hidalgo eran suyas las de San Nicolás Ulapa, Atotonilco y Montero (Pérez y Rivera, 2012, p. 788); poseía gran parte de los terrenos que a principios del siglo XIX pertenecieron a Alonso Marcilla Teruel García, décimo conde de Moctezuma Tultengo (Ramírez, 2010), y que luego pasaron a formar parte de la hacienda San Servando. Seguramente esas tierras fueron vendidas por los Moctezuma a consecuencia de la ley de 1823, que desvinculó cacicazgos, fideicomisos y mayorazgos.

San Servando tenía dos ranchos anexos: Teocalco y Santa Bárbara. Desde su casco hasta el límite poniente en el cerro Magoni, municipio de Tula de Allende, incluía los terrenos más fértiles del valle de Tula. En el proceso de expansión territorial había absorbido completamente pueblos como Teocalco y Tlahuelilpan. Antes de ser cercenada por el primer reparto ejidal en la zona, ocurrido en 1918, San Servando cubría una superficie de 14.638,80 hectáreas, de las cuales aproximadamente 3.631,83 eran de riego. Contigua a esa unidad productiva se localizaba Ulapa, cuya extensión era menor, pues solo cubría 12.687 ha. ${ }^{4}$

\section{SISTEMAS DE RIEGO}

San Servando fue una unidad productiva cuyo casco, que conjuntaba los edificios principales, se construyó durante el virreinato en la ribera del río Salado. A ambas márgenes de ese cauce contaba con tierras irrigadas mediante siete canales principales, que se alimentaban de ríos constitutivos de la cuenca del río Moctezuma. Un canal nacía en el río Tepeji, subcuenca del río El Salto (RH26Dm), que se origina en la barranca del Gavillero y que desde 1922 desemboca en la presa Requena (anteriormente lo hacía en el río Tula). Los otros seis canales se alimentaban del río Salado, principal corriente de la subcuenca del mismo nombre, que luego de varios kilómetros de desarrollo desemboca en el río Tula (Maderey y Carrillo, 2005, p. 27). Primero hablaremos brevemente del riego originado en el río Tepeji, enseguida, de los canales conectados al río Salado, y al final del apartado estudiaremos los que surcaban al interior de la hacienda.

El reducido caudal del río Salado, sumado a la cantidad de pueblos ribereños con derechos al uso del agua de ese cauce, así como el constante aumento en la superficie irrigada, por años motivaron litigios judiciales entre usuarios (Ramírez, 2019). Justamente fueron las dificultades que los dueños de las haciendas San Miguel Chingú y San Servando enfrentaron para acceder al agua del río Salado, lo que los motivó para que a mediados del siglo XVIII construyeran un canal de riego alimentado por el lejano río Tepeji. De ese cauce se surtía de agua la zanja Romera, canal de riego de $37,71 \mathrm{~km}$ de largo que nacía en una presa localizada en el barrio la Romera, en Tepeji, y cruzaba por tierras de las haciendas Caltengo, Guadalupe, El Salto, Molino de Jaso 
(hoy Cementos Cruz Azul), el condado Moctezuma Tultengo y del pueblo de Tula. ${ }^{5}$ A principios del siglo XX la Compañía de Luz y Fuerza de Pachuca construyó la presa y el canal Requena en un lugar cercano al nacimiento de la zanja. Ambos fueron utilizados para irrigar los terrenos al occidente y al oriente de dicha corriente (Herrera, 1930, pp. 11-21). Sin embargo, la nueva obra la Romera continuó funcionando. Muestra de ello es la solicitud de confirmación de uso de agua del río Tepeji que en 1912 hizo Lorenzo Astivia, apoderado de Trinidad y Piedad Iturbe. En ella mencionó que la hacienda había hecho uso continuado del agua desde 1742, año en que la audiencia de la Nueva España se la mercedó. ${ }^{6}$ San Servando disfrutó íntegra el agua de ese conducto hasta aproximadamente 1921, cuando parte de las tierras por donde pasaba fueron expropiadas para cumplir con la dotación ejidal.

El sistema de riego más antiguo nacía del río Salado. De él derivaban varios canales utilizados para el riego agrícola y el abasto doméstico. El sistema iniciaba en una presa construida en las inmediaciones del pueblo de Tlamaco, municipio de Atitalaquia, de la cual nacía una zanja cuya función era el desfogue de las avenidas del río hacia las tierras al poniente. Con ella se regaban los campos de Atitalaquia, Chingú y San Servando. A poca distancia del nacimiento de ese canal se conectaba al río otro canal conocido como Dendhó, por el que Chingú, los barrios de Dendhó, Cardonal y Doxey conducían agua a sus cultivos. Al margen oriente del río había una tercera zanja, conocida como de los Tres Pueblos, mediante la cual se transportaba el agua al pueblo de Atitalaquia y a los localizados río abajo como Tlaxcoapan y Tlahuelilpan. Existen indicios que nos permiten afirmar que parte de este sistema ya existía en el siglo XVI (Ramírez, 2019), aunque también es probable que date de tiempos precortesianos como lo sugieren los recorridos de superficie efectuados por arqueólogos (Mastache, 1976). La presa Tlamaco, también conocida como la Reina, data de 1544. Su existencia constantemente causó pugnas entre los usuarios porque generalmente el volumen del río era sumamente exiguo, de manera que al represar el agua difícilmente podían acceder a ella los habitantes y agricultores localizados río abajo. A pesar de que la audiencia de la Nueva España reiteradamente ordenó su demolición, tanto los agricultores de Atitalaquia como los hacendados insistieron una y otra vez en su reconstrucción. Mas no solo el exiguo caudal del río causaba desacuerdos, también lo hacía el exceso de lluvia. Durante el virreinato esa presa fue objeto constante de remodelaciones, reconstrucciones y cambios de ubicación, debido a que en temporada de lluvia la fuerza de las avenidas del río la derruía. Cada nueva obra que se erigió ocasionó litigios y propició, a su vez, la conformación o rectificación de pactos entre usuarios. ${ }^{7}$

A grandes rasgos este era el sistema de riego del que se beneficiaba la hacienda San Servando hasta principios del siglo XIX. Durante esta centuria sus dueños construyeron nuevas presas y canales que surcaron las tierras en su interior y únicamente eran para su beneficio. Antes de continuar profundizando en los sistemas de riego de la hacienda haremos un paréntesis para abordar los aspectos relativos a la administración del agua.

De acuerdo con Jacinta Palerm (2010), durante el virreinato novohispano la gestión del agua fue de tipo acéfala, es decir, no existían instituciones generales que vincularan a los usuarios para ese fin. Esto no quiere decir que no se contara con autoridades locales para esos menesteres. Estudiosos del tema hídrico han encontrado que el acceso al agua se lograba mediante acuerdos horizontales, algunas veces puestos por escrito, en los que se indicaba los días y horas que cada uno podía gozarla (Palerm, 2010). La comunidad tenía un papel preponderante en la administración del líquido, el mantenimiento del sistema y en dirimir litigios o turnarlos a las autoridades. En este sentido, encontramos que la zanja poniente, que surtía agua a San Servando, Chingú y Doxey, por muchos años fue administrada por los mismos regantes, quienes acordaron que Chingú debía dejar correr el agua durante doce horas continuas diariamente, pero únicamente en el periodo de estiaje, es decir, desde el primero de septiembre hasta primero de marzo. Por otro lado, desde al menos el siglo XVIII quedaron estipulados los acuerdos para el acceso al agua de la zanja de los Tres Pueblos, según los cuales Atitalaquia podía gozarla desde la madrugada hasta la puesta del sol. A partir de ese momento regaban los pueblos río abajo, esto es, Tlahuelilpan y Tlaxcoapan. ${ }^{8}$ Esos convenios, con algunas transformaciones, se mantuvieron vigentes hasta la década de 1920. 
Gran parte del siglo XIX la administración del sistema de riego derivado del río Salado estuvo a cargo de las asambleas municipales de Tlaxcoapan y Atitalaquia. Esta no fue una situación novedosa, verificada solo en el caso que nos ocupa, más bien el uso, propiedad y posesión del agua fue por lo general un asunto de los ayuntamientos, pueblos, hacendados o corporaciones religiosas, que mantuvieron bajo su control el dominio del agua amparados en la legislación colonial (Ver Margadant, 1989), la cual contemplaba figuras legales como mercedes, composiciones o repartimientos. Los usos del agua eran materia del derecho civil, y es por ello que los conflictos entre usuarios se dirimían ante autoridades judiciales (Camacho y Chávez, 2017; Escobar, 2013 y 2009; Sánchez y Escobar, 2008). En opinión de Jacinta Palerm (2010), en el caso mexicano se puede observar una continuidad de la estructura de gestión del agua entre el periodo virreinal y gran parte del siglo XIX.

A raíz de conflictos legales que los pueblos ribereños sostuvieron con la hacienda San Servando por el acceso al agua, en 1872 se renovaron los antiguos acuerdos (Sandré y Sánchez, 2011, p. 219). En el convenio que ese año signaron, y que posteriormente se erigió en reglamento, fueron plasmados los derechos que cada usuario tenía. Ahí se asentó que el agua mansa continuaba perteneciendo, como antaño, a los pueblos de Atitalaquia, Tlaxcoapan, Tlahuelilpan y San Servando, mientras que el agua de las avenidas o torrencial era de los anteriores, además de Chingú y el barrio de Doxey. Aquellos tres pueblos podían acceder al agua mansa durante ocho horas diarias a través del canal de los Tres Pueblos; mediante la zanja Dendhó se conducía el agua torrencial hasta Chingú, Doxey y a las tierras de los pueblos de Atitalaquia y Tlahuelilpan localizadas en la banda poniente del río. ${ }^{9}$ Advertimos que a finales del siglo XIX el sistema de riego era semejante al que existió durante el virreinato.

A finales del siglo XIX los acuerdos, ahora convertidos en reglamento, se pusieron por escrito en 1882 ante notario público, y la administración y gobernanza del agua pasó del control del ayuntamiento a los usuarios. El reglamento, conocido como Contrato de aguas, fue vigilado y sancionado por una junta directiva o junta de agua llamada Sociedad Agrícola. La junta directiva estaba compuesta por cinco personas electas entre los usuarios, representantes de los regantes de cada una de las zonas de riego que establecía el Contrato de aguas, es decir, las vegas de Atitalaquia, Dendhó y el barrio de Tlalminulpa. Entre las funciones de la junta estaba la de vigilar el reparto y distribución equitativa del agua, efectuar contratos con nuevos regantes, realizar gestiones ante autoridades competentes, resolver quejas y reclamaciones de los usuarios; tenía también la facultad de remover a los miembros de la directiva, promover juicios con terceros, además de reformar o adicionar cláusulas del contrato acordes a las necesidades y la experiencia. El Contrato preveía que para atender los gastos necesarios de la junta cada regante debía aportar una suma de dinero proporcional a la superficie irrigada. El mantenimiento de la infraestructura se costeaba con aportaciones monetarias de todos los miembros y con trabajo comunitario (Sandré, y Sánchez, 2011, pp. 220-224). No obstante los cambios legislativos en materia hídrica de finales del siglo XIX y principios del siglo XX, la Sociedad Agrícola y el Contrato continuaron funcionando hasta 1929, asunto sobre el que volveremos más adelante. ${ }^{10}$ Israel Sandré y Martín Sánchez (2011) han demostrado que la elaboración de reglamentos de agua entre pueblos de indios, hacendados o rancheros fue un fenómeno común en todo México a finales del siglo XIX. Palerm (2010) considera que los elaborados antes de la publicación de la ley del 5 de junio de 1888 son un tipo de acuerdo horizontal. Los miembros de esas asociaciones establecían sus propias reglas y formas de elección de sus autoridades. En ellos la comunidad de regantes dictaba la forma en que se debían organizar para dar mantenimiento a la infraestructura hidráulica, así como para asegurar la distribución equitativa del agua, evitar posibles conflictos y en caso de haberlos cómo debía procederse (Sandré, 2004). No debemos confundir estas comunidades de regantes con las que el estado mexicano creó entre 1910 y 1930 . Aquellas eran asociaciones espontáneas, mientras que estas últimas respondieron a leyes decretadas en ese periodo. A pesar de que ambas formas de organización tienen orígenes diferentes, presentan estructuras y formas organizativas semejantes por lo que probablemente existan continuidades. 
Además de las zanjas mencionadas hasta el momento, San Servando contaba con otras presas y canales, que, a diferencia de los anteriores, únicamente eran utilizados para regar sus campos de cultivo. Hacia 1919 parte del riego de San Servando y Ulapa, derivado del río Salado, se efectuaba mediante dos presas y tres canales localizados río abajo del sistema antes relatado. La primera toma se encontraba a menos de un kilómetro del casco de la hacienda río arriba; ahí estaba la presa de derivación conocida como Las Cadenas. Cuando el río llegaba a la presa era dividido por ella en dos brazos que concluían en dos construcciones de mampostería. Uno conocido como Canal de la Derecha -con 100 metros de desarrollo y capacidad para 859 litros por segundo para el riego de entre 197,2 y 230 ha- surcaba las tierras al oriente entre el río y el casco de la hacienda. El segundo brazo lo conformaba el canal Barrera -que con sus $1,5 \mathrm{~km}$ de longitud bañaba las tierras al poniente del río-; estaba diseñado para conducir $5.120 \mathrm{l} / \mathrm{s}$ y regaba entre 1.056,80 y 1.185,6 ha. Río abajo había otra presa de vigas llamada Guadalupe y había sido construida en 1899. De ella derivaba la zanja Colorada o Xitejé, mediante la que se conducía agua hacia las tierras de San Servando y las de Ulapa, donde concluía. Tenía capacidad de $1.108,1 \mathrm{l}$ /s para el riego de entre 156,24 y 278,4 ha.

De acuerdo con la información proporcionada por Lorenzo Astivia, apoderado de las herederas de Manuel Iturbe, hacia 1919 San Servando regaba 1.410,76 ha con agua del río Salado. Años después, la Comisión Nacional Agraria informaba que antes de 1924 la hacienda poseía 2.221,07 ha bañadas por la zanja Romera.

${ }^{11}$ De esta manera, a principios del siglo XX San Servando irrigaba aproximadamente 3.631,83 ha con ambos cauces, de las cuales 1.082,46 le fueron expropiadas entre 1918 y 1940. Con algunas modificaciones, estos sistemas de riego actualmente continúan siendo utilizados por los ejidatarios de la zona.

\section{Fragmentación de la hacienda, 1918-1940}

El artículo 10 de la ley agraria de 1915 dio la posibilidad a los propietarios afectados de que en el término de un año a partir de la publicación de la resolución presidencial acudieran a los tribunales a deducir sus derechos, sin especificar en qué tribunales serían atendidos ni el procedimiento para hacerlo. Esta vía estuvo vigente hasta 1932. ${ }^{12}$ Ante esas imprecisiones los afectados recurrieron a la Suprema Corte de Justicia de la Nación en busca de un amparo. Dicho artículo abrió la puerta a un alud de reclamaciones contra al gobierno mexicano por parte de hacendados directamente afectados por la reforma agraria (Baitenmann, 2017). Como ha demostrado Edgar Mendoza (2010), en su estudio del valle de Teotihuacán y Otumba, los hacendados "resistieron" a la reforma agraria mediante diversas estrategias, como el juicio de amparo, pero igualmente recurrieron a alianzas con jueces y autoridades locales para retrasar la expropiación de tierras.

En su fracción XVII, inciso a, el artículo 27 de la Constitución de 1917 dio libertad a los estados para legislar en materia agraria (Constitución Política de los Estados Unidos Mexicanos, 1917). La primera ley agraria del estado de Hidalgo, también conocida como decreto 122, data de 1923 y fue dictada por el entonces gobernador Antonio Azuara; su objetivo era proteger a la pequeña propiedad. No es de extrañar esa medida, pues la política agraria de los hermanos Azuara, que gobernaron la entidad entre 1921 y 1924, se distinguió por proteger la propiedad privada, en particular en la región de Huejutla, de donde eran originarios. Esta ley, junto con el artículo 10 de la emitida el 6 de enero de 1915, sirvió de base a jueces de distrito para dictar en favor de los hacendados en caso de que se enfrentaran a la expropiación. El decreto 122 dio la posibilidad para que latifundistas fraccionaran sus propiedades mediante venta, traspaso, donación o herencia, siempre que lo hicieran antes de haberse publicado la solicitud de reparto agrario (San Pedro, 2014).

El decreto 122 está conformado por nueve capítulos, 62 artículos y dos transitorios, en los que se abordan asuntos como la superficie de tierra que un particular podía poseer, y la forma y plazos en que debía efectuarse el fraccionamiento de los latifundios. En cuanto a la superficie que un individuo, sociedad o institución podía conservar, el artículo 11 preveía que la misma se reducía a un total de 1.300 ha, entre las que se podían incluir diferentes clases de tierra cada una con límites establecidos. Asimismo, la superficie a conservar podía ser mayor en caso de requerirlo la actividad económica que en ella se efectuara, asunto que requería de un decreto 
especial dado por el Congreso del Estado. No es difícil imaginar entonces que tal prerrogativa permitiera la supervivencia de más de un latifundio. Toda propiedad que excediera los límites señalados se consideraba latifundio, por lo que en el plazo de un año sus propietarios estaban obligados a fraccionarlo a título de interés público, y en caso de no hacerlo voluntariamente, el gobierno del estado se obligaba a efectuarlo pero no de manera automática, pues la ley estipulaba que el fraccionamiento solo se realizaba en caso de que la tierra fuese solicitada. Sin embargo, más allá de las circunstancias particulares el propietario afectado tenía derecho a señalar la ubicación de la extensión de tierra que más fuera de su agrado para poder conservarla. ${ }^{13}$

De acuerdo con Edgar Roldán (2018), el reparto agrario en Hidalgo inició entre 1917 y 1920, aunque Javier Hernández (2000) documenta la restitución de tierras a varios centros de población ya desde 1915. Durante los años que van desde 1917 a 1920, correspondientes al gobierno de Nicolás Flores Rubio, las principales zonas afectadas con el reparto agrario fueron las del sur del estado, mientras que los principales latifundios expropiados fueron los de Tlahuelilpan, Ulapa, San Javier, San Ignacio, San Antonio y El Marqués. Roldán (2018) encuentra que entre 1917 y 1940 en Hidalgo se formaron 534 ejidos y se ampliaron 472, a los que se dio un total de 648.017 ha para el beneficio de 69.844 agricultores. De esa superficie, entre 1917 y 1920 se dotó tan solo el 4,6 \%; entre 1921 y 1930 aumentaron las dotaciones a 31,6 \%, mientras que entre 1931 y 1940 la misma acción agraria alcanzó el 39,3 por ciento. Cabría preguntarse por el tipo de tierra que les fue entregada a los ejidatarios. De acuerdo con Escobar (2007), la tendencia nacional al inicio de la presidencia de Lázaro Cárdenas indica que las mejores tierras, las irrigadas, estaban aún en manos de latifundistas. En muchos casos los hacendados se opusieron férreamente a la entrega de tierras irrigadas, al respecto Aboites ha documentado casos semejantes en La Laguna y valle del Mayo (Aboites, 1997 y 1991).

En los hechos varias haciendas fueron invadidas apenas conocerse la ley agraria, incluso antes de que eso ocurriera como en el caso que aquí nos ocupa. Así, por ejemplo, tres días antes de ser expedida esa ley las autoridades municipales de Tula dieron en posesión las tierras de Ulapa y San Servando a vecinos de los pueblos de Tetepango, Mixquiahuala y Tlahuelilpan. ${ }^{14}$ Posteriormente, los invasores solicitaron la dotación de ejidos conforme a lo prevenido en la legislación en la materia. Algunas veces los hacendados lograron, mediante acuerdos políticos, fraccionar sus propiedades y repartirlas entre sus parientes y allegados como en el caso de las haciendas del valle de Teotihuacán (Mendoza, 2010). Para las propietarias de San Servando esa vía siempre les fue negada, por lo que en un breve periodo de tiempo vieron expropiadas sus tierras e "invadidos" los sistemas de riego que habían aprovechado en conjunto con los agricultores de los alrededores. Por mucho tiempo Trinidad y Piedad Iturbe intentaron impedir el reparto agrario y con ello la fragmentación de la hacienda. Pusieron en venta sus tierras entre los agricultores de la región y solicitaron al gobierno de Hidalgo que se les permitiera fraccionar sus propiedades para venderlas, pero tales opciones les fueron negadas.

A principios del siglo XX, españoles afectados por el movimiento armado de la revolución presentaron al gobierno mexicano, a través de la Secretaría de Relaciones Exteriores, memoriales de las afectaciones a su propiedad con la intención de que se les devolvieran sus bienes o pagaran los daños. En la década de 1920 Trinidad solicitó una indemnización que ascendía a 600.126,24 pesos por la ocupación de sus tierras, requisición de dinero, despojo de semillas, semovientes y cosechas. Algunos de esos expedientes recibieron fallo favorable por la Comisión Mixta Hispano-Mexicana de Reclamaciones, pero el de Trinidad Iturbe recibió una rotunda negativa (Pérez y Rivera, 2012, pp. 771-798). Además de esas pérdidas, madre e hija se tuvieron que enfrentar la expropiación ordenada por el gobierno mexicano.

Antes de la reforma agraria la hacienda de Ulapa estaba conformada por 12.687 ha, cuyas calidades desconocemos, su fragmentación ocurrió en un tiempo muy breve, entre 1919 y 1926. Así, en 1919 Tepeitic recibió 1.500 ha, un año después se formó uno de los ejidos más extensos de Hidalgo, pues dotaron 7.853 ha a Mixquiahuala; en 1921 se tomaron de la hacienda 2.017,5 ha para la formación del ejido de Tetepango y 285 para el de Tezontlale. Cinco años después de esas expropiaciones, que dejaron a la hacienda sin el $91,8 \%$ de su territorio, nuevamente se le quitaron 768,2 ha para la formación del ejido de Ulapa. Después de 1926 únicamente restaron a la hacienda 263,15 ha, cuyo destino ignoramos. El desmembramiento de 
San Servando, sin embargo, tomó más tiempo. ${ }^{15}$ Entre 1918 y 1940 se le expropiaron $14.028,37$ ha para la dotación de 14 ejidos y la ampliación de ocho, cifra que equivale al 95,8 \% del total de su antigua superficie. En un primer momento, durante el gobierno de Venustiano Carranza, las expropiaciones solo ascendieron a 1.255 ha, esto es, el 8,5\% del total de su superficie original. El único ejido beneficiado con el reparto en ese momento fue el de Tezontepec. En 1920, bajo la presidencia de Adolfo de la Huerta, se formaron dos ejidos más (1.301 ha, 8,8 \%), Tlahuelilpan y Doxey. Por esas acciones el apoderado de la familia Iturbe promovió juicio de amparo ante la Suprema Corte de Justicia sin obtener resultados favorables. El 39,73 \% de su superficie (5.817 ha) fue embargada entre 1921 y 1923 durante la presidencia de Álvaro Obregón, y a partir de ello se formaron nueve ejidos (Teltipan, San Gabriel, Ahuehuepan, Acayutlán, Atengo, Alpuyeca, El Llano, Nantzá y San Francisco Bojay). Por los siguientes diez años la hacienda no volvió a sufrir afectación, hasta 1933 cuando Abelardo L. Rodríguez ordenó que de ella se tomaran 3.703,37 ha para la dotación del ejido de Tula de Allende y para la ampliación del de Tezontepec. En 1934 este último recibió 2.577,37 ha. Con ambas acciones San Servando perdió el 42,9 \% de su superficie. Por su parte, la política agraria de Lázaro Cárdenas en la zona se enfocó en la ampliación de siete ejidos (El Llano, Ulapa, San Francisco Bojay, Ahuehuepan, Tlahuelilpan, Doxey y Atengo) que ocupaban 1.695 ha, y únicamente dio una dotación a Teocalco (257 ha). ${ }^{16}$ De manera que entre 1921 y 1923, y de 1933 a 1934, durante los periodos de gobierno de Álvaro Obregón y Abelardo L. Rodríguez, San Servando perdió el 82,6\% de su superficie.

Del total de los terrenos expropiados tan solo el 7,7 \% era de tierra de riego, lo que equivalía a 1.082,46 ha. Resulta importante resaltar que de las $12.076,37$ ha que se repartieron desde Venustiano Carranza hasta Abelardo L. Rodríguez, únicamente 689,46 fueron de riego y beneficiaron a solo dos ejidos, Tezontepec en 1934 y Tlahuelilpan en 1920. Mientras que 393 ha de riego se destinaron a la ampliación de los ejidos de El Llano, Tlahuelilpan, Ulapa, Teocalco y Doxey en los años 1935 y 1936. Cabe preguntarse por el destino de las otras 328 ha irrigadas con que contaba la hacienda. La gran mayoría de las resoluciones presidenciales, particularmente en el periodo de 1918 a 1923, no indican el tipo de tierra entregada a ejidatarios. En esta situación se encuentran 8.066 ha, un 57,5 por ciento del total. El resto de los terrenos enajenados eran de agostadero (4,3\%, 599 ha), temporal $(9,4 \%, 1.323,1$ ha), cerril $(8,3 \%, 1.168,52$ ha), y laborable $(12,8 \%$, 1.789,29 ha). Hacia principios de 1940 la familia Iturbe solo conservaba 609,73 ha de San Servando, las mismas que fueron dadas a fraccionadores para su venta entre particulares. Durante veinte años continuaron vendiéndose dichos terrenos a labradores de la región. A raíz del reparto agrario, en un breve periodo de tiempo que va de 1918 a 1921, San Servando no solo perdió una gran cantidad de tierras, sino también el control sobre gran parte de los canales de riego, a saber, aquellos que por siglos había compartido con los pueblos vecinos y también aquellos que se habían construido en su interior.

\section{EL REPARTO DEL AGUA}

Escobar plantea que la reforma agraria ocasionó una suerte de "tragedia" en las zonas rurales, pues fracturó y fraccionó sistemas de riego construidos a lo largo de siglos por pueblos y haciendas (2013, p. 267). En México muchos de los sistemas de riego existentes a principios del siglo XX eran de origen virreinal y luego del reparto agrario quedaron desarticulados y repartidos en múltiples ejidos. Ese proceso, así como sus particularidades, lo han documentado varios autores, para Morelos, Laura Valladares (2003), Martín Sánchez aborda la región del Bajío (2005); Edgar Mendoza documenta las galerías filtrantes en Tehuacán (2005); Rocío Castañeda estudia el valle de Santa Rosalía en Chihuahua (1995) y Atlixco en Puebla (2005); Gloria Camacho en Ocoyoacac (2008), Antonio Escobar en San Luis Potosí (2013) y Lourdes Navarrete en La Laguna (2003). Los estudiosos del tema han detectado que no se puede hablar de una reforma agraria, sino de varias, cada una con características diferentes, y con un impacto igualmente diverso sobre los sistemas de riego. A diferencia de otras regiones, las propietarias de la hacienda San Servando poco pudieron hacer para conservar bajo su control tierras y sistemas de irrigación. 
Con base en el artículo cuarto de la ley de aguas de 1910 Lorenzo Astivia, en nombre de Piedad Iturbe, solicitó la confirmación de agua del río Tepeji que la hacienda Tlahuelilpan conducía mediante la zanja Romera. En 1912 la Secretaría de Fomento, Colonización e Industria confirmó el derecho al uso de 468 $1 / s$, que correspondían a las tres cuartas partes del agua que surcaba por dicha zanja, ya que la otra cuarta parte pertenecía a Chingú. ${ }^{17}$ En el invierno de 1919 Astivia solicitó la confirmación de derechos de uso y aprovechamiento de agua del río Salado para el riego y entarquinamiento de San Servando. Para entonces la hacienda había sufrido solo una merma con la dotación de ejido a Tezontepec, pero entretanto se resolvía el expediente, en agosto de 1920 se formó el ejido de Tlahuelilpan, y en noviembre del mismo año el de Doxey. $\mathrm{Al}$ año siguiente, mientras la Secretaría de Fomento continuaba elaborando las inspecciones e informes necesarios a fin de confirmar el agua a las herederas de Manuel Iturbe, nuevamente se expropiaron tierras a San Servando para formar los ejidos de San Gabriel y Atengo, mientras que paralelamente la hacienda Ulapa fue cercenada con los ejidos de Mixquiahuala en 1920, y Tezontlale y Tetepango en 1921. Con esas dotaciones ejidales, entre 1918 y 1921 San Servando perdió totalmente el control de la zanja Colorada, pues quedó comprendida en los ejidos de Mixquiahuala, Tezontlale y Tetepango, más allá de que el único ejido al que la resolución presidencial le concedió la tierra y el agua fue el de Tlahuelilpan; los demás se apropiaron de ella junto con la infraestructura hidráulica. El Canal de la Derecha y la Presa de las Cadenas fueron absorbidos por el ejido de Tlahuelilpan, mientras que una parte del canal Barrera igualmente quedó en tierras de los ejidos de Doxey, Tlahuelilpan y Tezontepec. Igualmente, en el año de 1920 la hacienda perdió el control de la zanja poniente del río Salado, pues se la apropió el ejido de Doxey. ${ }^{18}$

Con base en el informe de inspección a las obras hidráulicas de San Servando, efectuado por Mariano Barragán en 1921, la Dirección de Aguas consideró que era posible confirmar el uso de agua del río Salado, pero que aún se requería la ejecución de modificaciones, en particular a la zanja Colorada. Por esto, se produjo una lluvia de oficios entre Astivia y la Secretaría de Agricultura y Fomento. En ellos se exponía que Astivia se negaba a efectuar los cambios solicitados, pues al dotar de ejidos a varios pueblos con las tierras de la hacienda, los ejidatarios habían tomado el agua de los canales, y habían dejado a sus representadas sin posibilidad de regar, de manera que resultaba innecesario hacer modificaciones en una infraestructura que ya no podían usar. En la opinión del representante de las Iturbe, como muchos otros, la ley agraria solo daba tierra a los pueblos, pero no así agua. Un asunto que no quedó muy claro en las resoluciones presidenciales, mediante las cuales se concedieron ejidos, es si la tierra iba con el agua. En opinión de la Comisión Nacional Agraria, las tierras dotadas conservaban los "derechos de utilización de aguas de riego y enlame", es decir, el agua era accesión de la tierra. ${ }^{19}$ Esto no era admisible tanto para Astivia como para otros hacendados afectados.

En la práctica los agricultores favorecidos con reforma agraria hicieron uso del agua y canales de riego que habían sido de las haciendas San Servando y Ulapa, y que luego de las resoluciones presidenciales quedaron comprendidos en sus ejidos. En el informe que en 1922 se elaboró a solicitud de Astivia, al respecto de las obras de riego de las haciendas de las Iturbe, quedó claro que luego del reparto agrario el sistema de riego había sufrido importantes mermas. Por ejemplo, la zanja Colorada ya no pudo ser usada a pesar de las quejas del apoderado, pues pasó a ser utilizada por los ejidatarios de Tezontepec, Mixquiahuala, Tetepango, Tezontlale y Ulapa que fueron beneficiados con las tierras de Ulapa. Así, el Canal de la Derecha pasó a regar 170 ha del ejido de Tlahuelilpan y únicamente 60 ha de San Servando. El canal Barrera se utilizó para irrigar 90 ha del ejido de Tlahuelilpan y 200 de la hacienda. Mientras tanto, el agua del río Salado, que corría junto al casco de la hacienda, era también utilizada por el pueblo de Tlahuelilpan. El informe no expuso la gravedad del asunto para las Iturbe, pues para entonces los sistemas de riego ya no estaban bajo su control; más bien ellas dependían de que los ejidatarios les permitieran acceder al agua. Pero la pérdida no solo ocurrió con el agua del río Salado, sino también de la que provenía del río Tepeji. La zanja Romera quedó dentro de los ejidos de manera paulatina. Hacia 1922 se habían apropiado de parte de ella los ejidatarios de Doxey, Alpuyeca y El Llano. La hacienda terminó por perder el control de ese conducto con la creación de los ejidos de Bomintzhá (1927), Vindhó (1928), Teocalco (1935), Ignacio Zaragoza (1938) y Acoculco (1946). ${ }^{20}$ 
$\mathrm{Al}$ respecto de las "invasiones" a los canales de riego y el "robo" de agua, el Departamento de Concesión de Aguas recomendaba tener cautela y sugería informar a los ejidatarios -como posteriormente se hizo-que la hacienda se encontraba en juicio con el gobierno federal ante el fallo que los dotó de ejidos, por lo que era conveniente respetarle el acceso al agua, aunque los canales de riego pasaran por los nuevos ejidos. La creciente conflictividad generada por el acceso al agua entre nuevos y viejos usuarios llevó a las autoridades a plantear la necesidad de reglamentar el acceso al agua del río Salado, a fin de lograr su distribución equitativa. ${ }^{21}$

Cuando se resolvió en favor de la hacienda el punto relativo a la modificación de las obras hidráulicas, un nuevo problema entorpeció la confirmación de agua. Las Iturbe interpusieron amparo por lo que consideraban un abuso de los ejidatarios y el estado mexicano, por haber invadido sus canales de riego y por la inminente reglamentación del río Salado. Por esto todo trámite relativo a la confirmación se detuvo hasta que los tribunales resolvieran. Posteriormente el gobierno mexicano solicitó a Piedad Iturbe renunciar a la nacionalidad checa, la cual había adoptado luego de su matrimonio con el príncipe Max Egon de Hohenlohe. A pesar de que la secretaría en más de una ocasión dio concesiones de agua a empresas o individuos extranjeros, en este caso consideraba que si la familia quería obtener la confirmación, Piedad Iturbe debía renunciar a su nueva nacionalidad, cosa que por supuesto no sucedió. ${ }^{22}$

Ante la pérdida de cosechas en la hacienda, en 1922 Lorenzo Astivia solicitó a la Secretaría de Agricultura y Fomento que se reglamentara el uso del agua del río Salado, pero sin renunciar al amparo que había solicitado ante esa acción. En 1923 se falló en contra de la hacienda en dicho juicio. En julio de ese mismo año Astivia interpuso un recurso de revisión por lo que el expediente se turnó a la Suprema Corte de Justicia de la Nación. Luego de concluida la revisión del caso, finalmente en 1924 se concedieron a San Servando 1000 l/s durante 17 días y medio, derivados del Canal de la Derecha, y 5000 l/s por 21 días conducidos por el canal Barrera. Para entonces ya se había perdido por completo el control sobre la zanja Colorada a manos de ejidatarios, mas no se le dio el título de confirmación hasta tanto se lograra un reglamento de agua, asunto que requirió de algunos años más. ${ }^{23}$

En la década de 1920 el único ejido que formalmente había recibido tierras de riego como parte de la dotación fue el de Tlahuelilpan. Posteriormente, de 1933 a 1936 y en 1940, las resoluciones presidenciales relativas a ampliación o dotación de ejidos explícitamente otorgaron tierras irrigadas a Tezontepec, El Llano, Tlahuelilpan, Ulapa, Teocalco y Doxey. Con ellas los ejidos terminaron por absorber los canales Barrera y Derecha. La superficie irrigada que fue expropiada a la hacienda San Servando por orden presidencial ascendió a 1.082,46 ha, seguramente las otras 328 ha también de riego correspondían a las invadidas por los ejidatarios durante el proceso.

\section{JUNTAS DE AGUA}

La nueva multitud de usuarios del agua y la creciente conflictividad que había ido en aumento desde finales del siglo XIX llevaron a que en 1922 la Secretaría de Agricultura vislumbrara la necesidad elaborar un reglamento de agua mediante el cual quedaran establecidos los derechos de cada uno. En opinión de esa secretaría, para evitar el despojo de agua a la hacienda de Tlahuelilpan debía replicarse el ejercicio practicado en la de Hueyapan y Santa María Nativitas; esto es, nombrar un ingeniero para que luego de una inspección fijara tanto a la hacienda como a los ejidos la parte proporcional de agua que cada uno podía usar, y, en caso necesario, se ordenaría la construcción de las obras de irrigación faltantes para asegurar el reparto. ${ }^{24}$ Pero sucedió lo contrario, la tensión por el acceso al agua entre pequeños propietarios, hacendados y ejidatarios producida por la ley de 1915 continuó vigente e incluso se fortaleció con la insistencia del gobierno federal por crear reglamentos y juntas de agua, que trastocaron los antiguos acuerdos en aspectos especialmente delicados como el volumen de agua repartido y su gobernanza. 
Si bien la ley de aguas de 1910 contempló la reglamentación del agua como una de las facultades del ejecutivo federal, dicho fenómeno cobró fuerza con la Ley de Aguas de Propiedad Nacional de 1929. A través de ella el estado pudo organizar a las comunidades de regantes, aunque no a todas, mediante asociaciones de usuarios, luego conocidas como juntas de agua (Palerm, 2009, p. 196). Las juntas tenían como función vigilar el cumplimiento de los lineamientos establecidos en el reglamento, la conservación de las obras de irrigación, turnar conflictos entre usuarios a la Secretaría de Agricultura y Fomento, y proponer a esa instancia la construcción de nuevas obras (Sandré, 2004). Estas juntas, a diferencia de las que hablamos atrás, fueron controladas por el gobierno federal a través de ingenieros, inspectores y delegados, cuyo gran poder los convirtió en verdaderos “déspotas hidráulicos” (Aboites, Birrichaga y Garay, 2010, p. 29).

El proceso de federalización del agua llevó aparejado el constante interés por reglamentar los usos del agua. Para Israel Sandré ese fenómeno fue la respuesta a la naturaleza diversa de los aprovechamientos existentes, ya que el estado se enfrentó a un contexto en el que en algunos ríos los aprovechamientos eran precarios, otros se efectuaban amparados en concesiones dadas por el estado, y algunas veces el uso del agua se efectuaba sin permiso alguno. Además, existía una gran cantidad de irregularidades para acceder al vital líquido, desde inequidad producto de las actuaciones de actores locales hasta problemas relacionados con la infraestructura misma. Laura Valladares (2003) considera que la creación de las juntas de agua en el siglo XX fue la respuesta necesaria del gobierno federal ante la creciente conflictividad por el acceso al agua que propició la reforma agraria. Nosotros nos adherimos a este último punto de vista, pero además consideramos que si bien las juntas de agua fueron creadas con la intención de lograr un acceso equitativo al agua, en la práctica propiciaron conflictos entre viejos y nuevos usuarios. Por otro lado, las juntas igualmente transformaron dos aspectos medulares de los antiguos sistemas de riego: la organización social y las obras hidráulicas. Estos aspectos, al igual que los antes relatados, detonaron enfrentamientos de aquellos que se vieron afectados por cambios en el volumen de agua recibido.

El nuevo reglamento de aguas del río Salado, que sustituyó al acuerdo decimonónico, entró en vigor a finales de 1929. Sin embargo, lejos de solucionar la distribución del agua, generó un alud de desacuerdos y quejas. Dos fueron los principales problemas detectados por la Secretaría de Agricultura y Fomento: la administración de los recursos monetarios y la distribución del agua se continuaban realizando como de costumbre, es decir, se involucraron en la gestión las asambleas municipales a pesar de no ser de su competencia; además, cada pueblo mantenía sus propias tesorerías, por lo que los recursos no llegaban a la junta, y finalmente, los grupos de poder local al mando de la junta decidieron unilateralmente qué terrenos regar, por lo que otros usuarios se vieron afectados. $\mathrm{Al}$ año siguiente se intentó poner en marcha un nuevo reglamento, que solo logró poner en evidencia las históricas fricciones entre Tlahuelilpan y su cabecera municipal, Tlaxcoapan. Por ello es que a pocos días de su entrada en vigor ese reglamento fue derogado. En 1931 se ideó un tercer proyecto de reglamentación, que ese mismo año entró en vigor, pero que no solucionó los conflictos de la comunidad de regantes, ni los que esta tenía con la asamblea municipal y con el comité administrativo de la junta. ${ }^{25}$ Sin embargo, en ninguno de esos tres reglamentos fue contemplada San Servando como usuaria del agua, seguramente por la considerable pérdida de tierras sufrida, pero tampoco estaban incluidos los ejidatarios. Únicamente conjuntaba a pequeños propietarios de Atitalaquia, Tlalminulpa, Tlaxcoapan y Tlahuelilpan que derivaban agua del río Salado mediante la presa Tlamaco y la zanja de los Tres Pueblos. ${ }^{26}$ Cabe preguntarse por los mecanismos que la Secretaría de Agricultura y posteriormente la Comisión Nacional de irrigación idearon para la gestión y gobernanza del agua de los sistemas de riego que estaban dentro de la hacienda San Servando y que pasaron a formar parte de los ejidos.

A un nivel regional, la problemática por el acceso al agua del río Salado era mucho más compleja. Hacia finales de la década de 1920 el número de concesiones de agua dadas superaba la capacidad del río. De los $7.591 \mathrm{l} / \mathrm{s}$ que había entre la salida del túnel de Tequixquiac y la presa Tlamaco tenían derechos la hacienda de San Sebastián (120 l/s), la Compañía de Luz y Fuerza de Pachuca ( 5.500 l/s), los pueblos de Apazco (100 l/s), Tlamaco (10 l/s), Atitalaquia, Tlahuelilpan, Tlaxcoapan (180 l/s), y únicamente restaban aproximadamente 
$1.671 \mathrm{l} / \mathrm{s}$ sujetos a las lluvias y el aumento del agua residual proveniente de la ciudad de México. Por ello en 1927 se declaró la veda del Salado, reiterada en 1931 y vuelta a confirmar en 1954. Hacia 1949 el gobernador de Hidalgo informó que el volumen del río Salado había disminuido debido a las concesiones otorgadas por el gobierno federal sin tomar en cuenta derechos de prelación que tenían los usuarios desde principios de esa centuria, a lo que se agregaban los abusos cometidos por los usuarios y la falta de obras limitadoras. Las sequías registradas en México en la década de 1940, aunadas al aumento en la superficie irrigada en la ribera del río y en el antiguo vaso del Lago de Texcoco, hicieron necesario que en 1951 se creara una comisión para estudiar los usos y consumos del agua del río Salado. ${ }^{27}$

\section{Conclusiones}

La ley agraria de 1915 benefició a miles de agricultores que recibieron tierras en calidad de ejidos. Gracias a ella se desmembró uno de los latifundios más extensos del suroeste del estado de Hidalgo, que por décadas estuvo en manos de los condes de la Cortina y posteriormente de las descendientes del diplomático Manuel Iturbe y del Villar. La expropiación de tierras a la hacienda San Servando Tlahuelilpan, ocurrida de 1918 a 1940, permitió la formación de catorce ejidos y la ampliación de ocho más. En ese periodo perdió 14.028,37 ha correspondientes al 95,83\% del total de su antigua superficie, pero los años más dramáticos para sus dueñas fueron los de 1921 a 1923 y de 1933 a 1934, cuando les fue confiscada el 82,63 \% de la superficie que conformaba la hacienda. Trinidad y Piedad Iturbe no solo vieron la expropiación de San Servando sino también la de Ulapa, que ocurrió en tan solo cinco años, de 1919 a 1926.

Si bien la ley agraria ordenó el reparto de tierra a los pueblos que carecieran de ella, en ninguno de sus artículos mandató explícitamente la entrega de agua a los nuevos ejidatarios. En la práctica, los agricultores favorecidos con las dotaciones agrarias hicieron uso del agua y canales de riego que habían sido de San Servando y Ulapa, y que luego de las resoluciones presidenciales quedaron comprendidos en sus ejidos. Aún queda por saber si posteriormente los ejidatarios solicitaron dotación de agua y si el ejido impactó de alguna manera en la productividad regional. La fragmentación territorial de ambas haciendas tomó más tiempo que el proceso que llevó a la pérdida de control sobre los sistemas de riego, que durante décadas o siglos había aprovechado y construido en conjunto con pueblos y haciendas vecinas. En particular, la formación de los ejidos ocurrida de 1918 a 1921 hizo que San Servando perdiera el control sobre sus principales conductos para el riego derivados del río Salado, mientras que la zanja Romera fue absorbida por los ejidos que a su paso se formaron, proceso que inició en 1922 y concluyó en 1946.

La reforma agraria abrió la puerta a las demandas de afectados no solo con la expropiación de tierras sino también con la apropiación del agua y obras hidráulicas por parte de ejidatarios. La invasión de canales de riego y el uso no autorizado del agua por parte ejidatarios levantó las quejas de las dueñas de Ulapa y San Servando, quienes enfrentaron sin éxito la política agraria e hídrica del estado mexicano. Este fue el primer gran golpe que recibieron los antiguos acuerdos ideados por los usuarios para la gestión y acceso al agua, forjados a través de siglos de convivencia relativamente pacífica. La tensión ocasionada se agravó a finales de la década de 1920. En ese contexto, el gobierno federal planteó la reglamentación del río Salado con el objetivo de lograr la distribución equitativa del agua entre los usuarios y poner fin a la conflictividad producida por la reforma agraria. Mas el proyecto fracasó; no contempló como regantes a la hacienda y ejidatarios, y tampoco puso fin a las tensiones, por el contrario, las aumentó. El caos propiciado por la política agraria e hídrica federal llevó a declarar la veda del río Salado. Sin embargo, no se solucionaron problemas que uno a uno se fueron acumulando: contaminación del agua de la cuenca del río Tula, distribución y administración eficiente del agua. 


\section{REFERENCIAS}

Aboites, L. (1997). El agua de la nación. Una historia politica de México (1888-1946). México: CIESAS.

Aboites, L. (1991). La política en el proceso agrario norteño, 1920-1940. Estudios sociales. Revista de Investigación del Noreste, 1(2), 5-44.

Aboites, L., y Estrada, V. (2004). Del agua municipal al agua nacional: materiales para una historia de los municipios en México, 1901-1945. México: CIESAS, CONAGUA, AHA, COLMEX.

Aboites, L., Birrichaga, D., y Garay, A. (2010). El manejo de las aguas mexicanas en el siglo XX. En B. Jiménez, M. L. Torregrosa, A. Aboites (Ed.). El agua en México: cauces y encauces (pp. 21-49). México: AMC, CONAGUA.

Baitenmann, H. (2017). Ejerciendo la justicia fuera de los tribunales: de las reivindicaciones decimonónicas a las restituciones de la reforma agraria. Historia Mexicana, 66(4), 2013-2072.

Camacho, G. (2008). Desamortización y reforma agraria en Ocoyoacac y Lerma, 1856-1930. En A. Escobar Ohmstede, et al. (coord.). En Agua y tierra en México, siglos XIX y XX (Tomo I, pp. 287-311). México: COLMICH, COLSAN.

Camacho, G., y Chávez, M. (2017). El dominio del agua y sus interpretaciones. El artículo 27 constitucional. En J. Olvera, et al. (coord.). La constitución política de los Estados Unidos Mexicanos, 1917-2017 a 100 años (pp. 391-424). México: UAEMEX.

Castañeda, R. (1995). Irrigación revolucionaria y reforma agraria: las continuidades de riego del valle de Santa Rosalía, Chibuabua, 1920-1945. México: CIESAS.

Castañeda, R. (2005). Las aguas de Atlixco. Estado, haciendas, fábricas y pueblos, 1880-1920. México: CONAGUA, AHA, CIESAS, COLMEX.

Castillo, L. (2008). La nobleza y el comercio en la Nueva España del siglo XVIII. El primer conde de la Cortina (1741-1795) (Tesis de licenciatura). UNAM- Instituto Cultural Helénico A.C., México.

Constitución Política de los Estados Unidos Mexicanos (1917). Recuperada de http://www.diputados.gob.mx/Leye sBiblio/ref/cpeum/CPEUM_orig_05feb1917_ima.pdf

Escobar, A. (2009). Manejo del agua en México. Bosquejo de la evolución institucional federal 1926-2008. En CONAGUA. Semblanza histórica del agua en México (pp. 61-73). México: CONAGUA.

Escobar, A. (2013). Cambios en el paisaje hidroagrario. ¿La revolución un detonante?: el caso de San Luis Potosí (1910-1940). Relaciones, 34(136), 265-315.

Hernández, J. (2000). Organización campesina y lucha agraria en el estado de Hidalgo, 1917-1940. México: UAEH.

Herrera y Lasso, J. (1930). Sistema de riego del Valle del Mezquital. Irrigación en México, 7(1), 11-21.

Herrera y Lasso, J. (1994). Apuntes sobre irrigación. Notas sobre su organización económica en el extranjero y en el pais. México: CIESAS, IMTA.

Ley del 6 de enero de 1915. Recuperada de http://www.ordenjuridico.gob.mx/Constitucion/CH15.pdf

Maderey, L. E., y Carrillo, J. (2005). El recurso agua en México: un análisis geográfico. México: UNAM/IG.

Margadant, G. F. (1989). El agua a la luz del derecho novohispano. Triunfo del realismo y flexibilidad. Anuario Mexicano de Historia del Derecho, 1(8), 113-146.

Martínez, J. (2004). Semblanzas de Académicos. Antiguas, recientes y nuevas. México: FCE.

Mastache, A. G. (1976). Sistemas de riego en el área de Tula, Hidalgo. En E. Matos Moctezuma (coord.). Proyecto Tula. Segunda parte (pp. 49-70). México: INAH.

Mendoza, E. (2005). Galerías filtrantes: la disputa por el agua del subsuelo en el valle de Tehuacán, 1900-1930. En J. M. Durán, M. Sánchez y A. Escobar (Ed.). El agua en la historia de México (pp. 221-236). México: CUCH, UDG, COLMICH.

Mendoza, E. (2010). Oposición al reparto agrario: los hacendados de Otumba y Teotihuacán, 1917-1930. Contribuciones desde Coatepec, 19, 61-88. 
Mendoza, E. (2013). Los municipios de San Gabriel Chilac y San Juan Teotihuacan ante la federalización de las aguas, 1888-1960. Relaciones, 34(136), 359-397.

Palerm, J. (2009). Las juntas de agua y las unidades de riego. En J. Palerm y T. Martínez (Ed.), Aventuras con el agua. La administración del agua de riego: historia y teoria (pp.195-2015). México: COLPOS.

Palerm, J. (2010). A comparative history, from the 16th to 20th centuries, of irrigation water management in Spain, Mexico, Chile, Mendoza (Argentina) and Peru. Water Policy, 12(6), 779-797.

Pérez, M., y Rivera, L. (2012). Propietarias españolas en México ante los efectos de la Revolución: pérdidas patrimoniales y búsqueda de indemnizaciones, 1910 a 1938. Revista de Indias, 72(256), 771-798.

Ramírez, V. C. (2010). Caciques y cacicazgos indigenas en la región de Tollan, siglos XIV y XVII. México: COLMICH.

Ramírez, V. C. (2019). Cuando el agua era nuestra. Volumen I. México: UAEH.

Roldán, E. I. (2018). Reparto agrario. Reestructuración del espacio y apropiación alimentaria en Hidalgo, México, 1917-1940. Revista de El Colegio de San Luis. Nueva Época, 8(16), 229-263.

Romero, L. (2002). Legalidad y conflictos por las aguas del Nazas: el litigio entre la Compañía del Tlahualilo y el gobierno de México, 1885-1912. Estudios de Historia Moderna y Contemporánea de México, 24, 45-78.

Romero, L. (2006). Conflicto y negociación por el agua del Nazas, 1888-1936. Del dominio público a la propiedad nacional. Región y sociedad, 18(36), 147-176.

Romero, L. (2007). El rio Nazas y los derechos de agua en México. México: CIESAS/Universidad Autónoma de Coahuila.

Rosas, S. F. (2013). Agua e industria en Puebla. El establecimiento de la fábrica textil La Covadonga, 1889-1897. Relaciones, 34(136), 223-264.

Sánchez, M. (1993). La herencia del pasado. La centralización de los recursos acuíferos en México. Relaciones, 14(54), $22-41$.

Sánchez, M. (2005). "El mejor de los títulos". Riego, organización social y administración de recursos hidráulicos en el Bajio mexicano. México: COLMICH.

Sánchez, M., y Escobar, A. (2008). El agua y la tierra en México, siglos XIX y XX ¿Caminos separados, paralelos o entrecruzados? En A. Escobar, M. Sánchez y A. M. Gutiérrez, (coord.) Agua y tierra en México, siglos XIX y XX (pp. 11- 48). México: COLMICH, COLSAN.

Sandré, I. (2004). Conflicto y gestión del agua. El caso de las juntas de agua en el Estado de México (1920-1950). Boletín del Archivo Histórico del Agua, 26, 35-44.

Sandré, I., y Sánchez, M. (coord.) (2011). El eslabón perdido. Acuerdos, convenios, reglamentos y leyes locales de agua en México (1593-1935). México: CIESAS.

Serrano, P. (2002). Conflictos por el agua entre la hacienda de Nogueras y las comunidades indígenas de Comala, Colima, 1920-1930. Boletín del Archivo Histórico del Agua, 20, 21-29.

Tercer Censo de Población de los Estados Unidos Mexicanos (1910). Recuperado de https://www.inegi.org.mx/progra mas/ccpv/1910/

Topete-Pozas, O., y Méndez-Zárate, A. (2019). Legislación estatal sobre los usos del agua en México: Una comparación entre los casos de Jalisco y Oaxaca, 1895-1905. Agua y Territorio, 14, 57-68.

Tovar, V., y Marín, C. (2009). El Palacio de Parcent. Madrid: Ministerio de Justicia/Secretaría General Técnica.

Valladares, L. (2003). Cuando el agua se esfumó. Cambios y continuidades en los usos sociales del agua en Morelos, 1880-1940. México: UNAM.

\section{Notas}

1 Poder ejecutivo (PE) (1-10-1920). Constitución Política del Estado de Hidalgo. Periódico Ofcial del Estado de Hidalgo (POEH), México.

2 PE (12-11-1923). Decreto determinando quiénes pueden solicitar y obtener tierras. Diario Ofcial de la Federación (DOF), México. 
3 Archivo Histórico del Agua, Aprovechamientos Superficiales (AHA, AS), exp. 17413, f. 24.

4 AHA, AS: exp. 17413, fs. 20r-24v; exp. 2272, f. 23r.

5 Archivo General de la Nación (AGN), México, Mercedes, vol. 72, fs. 270-274r.

6 AHA, AS, exp. 2272, f. 2.

7 AGN: Tierras, vol. 2998, exp. 8, fs. 122r-129r; Tierras, vol. 2369, exp.3, fs. 9r-18r.

8 AGN, Tierras, vol. 1470, exp. 4. f. 1r.

9 AHA, AS: exp. 59282, fs. 19v-25r; exp. 17414, fs. 70r-71r.

10 AHA, AS, exp. 7712, fs. 55, 103, 296-309.

11 AHA, AS, exp. 17413, fs. 13r-16v, 23r, 50r-54r.

$12 \mathrm{PE}$ (5 de enero de 1932). Decreto que reforma el artículo 10 de la ley agraria. $D O F$.

13 Gobierno del Estado de Hidalgo (GEH) (24-01-1924). Decreto 122. POEH.

14 Comisión Nacional Agraria (CNA) (8-01-1927). En revisión el expediente de Ulapa. POEH, p. 14.

15 Secretaría de Agricultura y Fomento (SAyF): (25-11-1919). Resolución del expediente de Tepeytic; (27-12-1920). Resolución del expediente de Mixquiahuala; (3-11-1921). Resolución del expediente de Tetepango; (28-10-1921). Resolución del expediente de Tezontlale; (23-04-1927). Resolución del expediente de Ulapa y Juandó, DOF.

16 AHA, AS, exp. 17413, f. 145v. En 1920 se dotó a Tlahuelilpan con 697 ha y a Doxey con 604 ha, que fueron tomadas de la hacienda. CNA: (1-11-1929). Visto el expediente de Tlahuelilpan; (8-05-1940). Visto el expediente de Atengo; (24-02-1918). Vista la solicitud de Tezontepec; GEH (8-05-1931). Visto el expediente número 110 en POEH. PE: (19-01-1921). Resolución del expediente de Doxey; (7-10-1921). Resolución en el expediente de Ahuehuepan; (31-10-1921). Resolución del expediente de Alpuyeca; (6-07-1922). Resolución del expediente de Nantzá; (5-07-1922). Resolución del expediente de El Llano; (17-09-1923). Resolución del expediente de Bojay. SAyF: (4-11-1921). Resolución del expediente de El Cerro y Munit; (9-05-1921). Resolución del expediente de San Gabriel; (9-05-1921). Resolución del expediente de Atengo;(21-03-1924). Resolución del expediente de Tula; (17-05-1933). Resolución del expediente de Tula. Departamento Agrario: (8-12-1934). Resolución en el expediente de Tezontepec; (11-02-1936). Resolución del expediente de El Llano; (4-02-1936). Resolución del expediente de Melchor Ocampo; (18-02-1936). Resolución del expediente de Bojay; (18-02-1936). Resolución del expediente de Ahuehuepan; (3-02-1936). Resolución del expediente de Tlahuelilpan; (18-02-1936). Resolución del expediente de Doxey; (18-10-1935). Resolución del expediente de Teocalco en DOF.

17 Secretaría de Fomento, Colonización e Industria (30-04-1912). Confirmación de derechos. Diario Oficial de los Estados Unidos Mexicanos.

18 AHA, AS: exp. 17413, fs. 15r-156r; exp. 2272, f. 23r; exp. 59282, fs. 19v-25r.

19 AHA, AS, exp. 17413, fs. 96r-99v, 147r, 157r, 198r.

20 AHA, AS, exp. 17414, fs. 218-219; exp. 17413, f. 208v. SAyF: (20-09-1927). Resolución del expediente de Bomintzhá. DOF; (16-07-1928). Resolución del expediente de Vindhó. DOF; DA: (18-10-1935). Resolución del expediente de Teocalco. DOF; (22-10-1946). Resolución del expediente de Acoculco. DOF.

21 AHA, AS, exp. 17413, fs. 146r, 148r, 208v; exp. 17414, fs. 218-219.

22 AHA, AS, exp. 17413, fs. 181, 209, 224r-225r, 238.

23 AHA, AS, exp. 17413, fs. 226r, 228r, 238r, 240r, $254 r$.

24 AHA, AS, exp. 17413, fs. 144-146r, 157r-157v.

25 AHA, AS, exp. 7712, fs. 42, 43, 55, 107, 122, 124, 126, 296- 309, 315, 412.

26 AHA, AS, exp. 17413, f. 227.

27 AHA, AS, exp. 7668, fs. 121r-123r.

\section{BY-NC-SA}

